\author{
Thomas-Thi Pluess \\ Daniel Hayoz \\ Mette M. Berger \\ Luc Tappy \\ Jean-Pierre Revelly \\ Burkhard Michaeli \\ Yvon A. Carpentier \\ René L. Chioléro
}

\section{Intravenous fish oil blunts the physiological response to endotoxin in healthy subjects}

Received: 13 June 2006

Accepted: 21 February 2007

Published online: 22 March 2007

(C) Springer-Verlag 2007

T.-T. Pluess - M. M. Berger - J.-P. Revelly ·

B. Michaeli · R. L. Chioléro (

CHUV, Department of Intensive Care

Medicine,

1011 Lausanne, Switzerland

e-mail: rene.chiolero@chuv.ch

Tel.: +41-21-3142002

Fax: +41-21-3143045

D. Hayoz

CHUV, Division of Hypertension and

Vascular Medicine,

1011 Lausanne, Switzerland

L. Tappy

University of Lausanne, Institute of Human Physiology,

1011 Lausanne, Switzerland

Y. A. Carpentier

Université Libre de Bruxelles, Laboratory

of Experimental Surgery,

Brussels, Belgium

\begin{abstract}
Objective: To assess the effects of intravenous fish oil fat emulsion on the metabolic alterations induced by lipopolysaccharide (LPS) challenge in healthy volunteers. Design: Two groups of eight healthy subjects were randomized to receive either two pharmacological doses of intravenous FO fat emulsion or no treatment. The FO group received twice $0.5 \mathrm{~g} / \mathrm{kg}$ $10 \%$ emulsion (Omegaven) 48 and $24 \mathrm{~h}$ before investigation. LPS ( $2 \mathrm{ng} / \mathrm{kg}$ ) was injected as a bolus on the investigation day. Systemic parameters, indirect calorimetry, heart rate variability, and platelet membrane phospholipid composition were measured. Results: Basal EPA and DHA content in platelet phospholipids was low $(0.28 \%$ and $2.54 \%$, respectively) and increased significantly after FO to $1.68 \%$ and $3.32 \%$. LPS induced reproducible
\end{abstract}

effects in all subjects. Fever was higher in the FO group than in controls; the difference was significant from $t_{120}$ until $t_{360}$. FO blunted the neuroendocrine response: the rise in plasma norepinephrine was sevenfold lower at $t_{120}$ while the ACTH peak was fourfold lower. Tumor necrosis factor $\alpha$ was significantly lower between $t_{360}$ and $t_{180}$ in the FO group. Conclusions: Two doses of intravenous FO fat emulsion modified the phospholipid composition of platelets in healthy subjects. FO blunted fever and increased the neuroendocrine and the inflammatory responses to LPS.

Keywords Endotoxin challenge . Lipopolysacharide - Fish oil supplement $\cdot$ Cytokines $\cdot$ Inflammatory response $\cdot$ Neuroendocrine response

\section{Introduction}

There are two main families of polyunsaturated fatty acids (PUFAs) $n-6$ and n-3. Among the n-3 PUFA family EPA and DHA are the most biologically active. Feeding with fish oil (FO) increases the proportion of EPA and DHA in the cell membrane phospholipids, including inflammatory cells. This decreases the synthesis of inflammatory eiconsanoids by numerous mechanisms [1]: (a) substrate competition, (b) inhibition of membrane arachidonic acid release, (c) synthesis of less potent eicosanoids, and (d) downregulation of proinflammatory cytokines, adhesion molecules, and of genes involved in inflammation.
It is generally considered that the oral administration of n-3 PUFA is required for several weeks to produce biological effects, precluding its use in acute conditions. However, it has recently been observed that intravenous administration of fat emulsions enriched with n-3 PUFA leads to rapid incorporation of n-3 fatty acids into phospholipids of platelets or monocytes [2]. Modulation of the inflammatory response in septic patients is desirable as excessive release of proinflammatory cytokines is associated with multiple organ failure; FO may thus prove to be a new therapeutic tool $[3,4]$.

Endotoxin (LPS) administration is an experimental, reproducible model of sepsis, mimicking some important as- 
pects of sepsis, and has the advantage of being short lived. This study examined whether two doses of intravenous FO downregulates the neuroendocrine and systemic responses to endotoxin in healthy volunteers in a prospective, randomized controlled study.

\section{Materials and methods}

Subjects

After approval by the institutional ethics committee and written informed consent we enrolled 16 men aged 18-35 years. Inclusion criteria were: good health, no medication, low fish consumption (less than twice a week), no nutritional supplementation, and particularly no FO supplements. A complete history, physical examination, and 12-lead electrocardiography were performed. Subjects had a mean age of $26.2 \pm 2.7$ years, body weight of $77.4 \pm 7.2 \mathrm{~kg}$, and body mass index of $23.4 \pm 1.9$.

\section{Study design and intervention}

Subjects were randomized to receive two pharmacological doses of intravenous FO 48 and $24 \mathrm{~h}$ before investigation, a dose of $5 \mathrm{ml} / \mathrm{kg}$ during $6 \mathrm{~h}$ each time $(100 \mathrm{ml}$ Omegaven 10\%: $10 \mathrm{~g}$ FO, providing 1.25-2.82 g EPA $\mathrm{n}-3) ; 1.44-3.09 \mathrm{~g}$ DHA (n-3), 0.1-0.7 g linoleic acid (n-6), max. 0.2 g $\alpha$-linolenic acid (n-3) and 15.0-29.6 mg $\alpha$-tocopherol; Fresenius Kabi, Bad Homburg, Germany). On the investigation day subjects came after an overnight fast, and were requested to void (urine discarded). Thereafter they remained recumbent for the next $8 \mathrm{~h}$. Two venous cannulas were inserted into the forearms: one for labeled glucose infusion and one for blood sampling. Blood samples were collected every 30-60 min. Endotoxin ( $2 \mathrm{ng} / \mathrm{kg}$, USP Rockville, Md., USA; lot no. 2) was administered as an intravenous bolus at time $t_{0}$.

\section{Blood collection and analysis}

In subjects who received FO fat emulsion two series of blood samples were collected (EDTA tubes): one before the first infusion and the second $48 \mathrm{~h}$ later, before LPS. Plasma was separated by low-speed centrifugation, and supernatant was centrifuged at 3,000/min for $10 \mathrm{~min}$ at $4{ }^{\circ} \mathrm{C}$. After separation of platelet lipid components by thin-layer chromatography the fatty acid pattern was analyzed only in the phospholipid fraction since mainly phospholipid fatty acids affect cell function. Triacylglycerol, phospholipids, and cholesterylesters were first separated by a two-dimension thin-layer chromatogra- phy. Fatty acids were analyzed by gas chromatography (Agilent, GC system, 6890A).

On the day of experiment blood was sampled during the protocol to determine hormone levels (insulin, glucagon, cortisol, ACTH, catecholamines), inflammatory markers [tumor necrosis factor (TNF) $\alpha$, interleukin (IL) 6, hsCRP), glucose, lactate, free fatty acids (FFA), and triglycerides. Plasma aliquots were stored at $-20^{\circ} \mathrm{C}$ or $-80^{\circ} \mathrm{C}$ (for FFA determination). Plasma insulin (Adaltis kit, Casalecchio di Reno, Italy), glucagon (Linco Research, St. Charles, Mo., USA) and cortisol (Diagnostic Products, Los Angeles, Calif., USA) were determined by radioimmunoassay; ACTH by chemiluminescence (Nichols Institute Diagnostics, San Juan Capistrano, Calif., USA); TNF- $\alpha$ by photometric enzyme-linked immunosorbent assay in streptavidin-coated microtiter plates (Roche, Mannheim, Germany); IL-6 by enzyme immunoassay using an enzyme-linked polyclonal antibody specific for IL-6 (Quantikine, R\&D Systems, Germany); hsCRP by turbidimetry on a Hitachi 917 (Roche). Plasma glucose and lactate concentrations were measured enzymatically (YSI 2300 STAT PLU, Yellow Spring, Ohio, USA); plasma FFA concentrations with a colorimetric method (Wako, Neuss, Germany). Urine was sampled from spontaneous voiding. Indirect calorimetry was performed using a canopy (Deltatrac2 model Datex, Kuopio, Finland). Resting energy expenditure (REE) was calculated from oxygen consumption $\left(\mathrm{VO}_{2}\right)$ and $\mathrm{CO}_{2}$ production $\left(\mathrm{VCO}_{2}\right)$ using the Livesey and Elia [5] equation.

\section{Vital functions}

Heart rate, respiratory rate, rectal temperature (Hellige, Servomed, Germany), noninvasive arterial blood pressure (Critikon Dinamap, Tampa, Fla., USA), cardiac output (thoracic bioimpedance, NCCOM3 cardiodynamic monitor, BoMed, Irvine Calif., USA) and transcutaneous oxygen saturation $\left(\mathrm{SpO}_{2}\right.$, Pulse oximeter Biox 3740, Ohmeda, Engelwood, Calif., USA) were monitored. Subjective symptoms such as muscle and head ache, and nausea/vomiting were recorded.

\section{Baroreflex sensitivity and heart rate variability}

Baroreflex sensitivity was derived from the spontaneous fluctuations in systolic blood pressure (SBP) and pulse rate. We used the sequence technique, which focuses on the baroreflex response to pressure transients $[6,7]$. Blood pressure (BP) was measured continuously by a Finapres BP Monitor (Ohmeda). SBP and pulse series were scanned automatically in search for spontaneous sequences of three or more consecutive heart beats in which a progressive SBP increase was followed, with 
a one-beat lag, by a progressive pulse rate lengthening or vice versa. The slope of the regression line between SBP and pulse interval values forming each sequence was taken as an estimation of the sensitivity of baroreflex cardiac modulation.

$\mathrm{ECG}, \mathrm{BP}$, and respiration were recorded at a sampling frequency of $200 \mathrm{~Hz}$. Beat-to-beat series of R-R interval were derived for heart rate variability (HRV) analysis as were series of SBP and pulse rate for baroreflex sensitivity estimation. Signals were edited manually from artifacts such as movements and noise. Beat-to-beat series were interpolated and resampled at $5 \mathrm{~Hz}$ to obtain an evenly sampled series and then split into data segments of $120 \mathrm{~s}$. Segments were overlapped by $50 \%$ and a fast Fourier transform spectrum was computed in each window. All fast Fourier transform spectra were averaged to obtain a single final spectrum, which was integrated over the low (LF; $0.05-015 \mathrm{~Hz})$ and high $(\mathrm{HF} ; 0.15-0.50 \mathrm{~Hz}$ ) frequency bands to characterize the LF and HF powers and LF/HF power ratio. Measures were recorded three times (30 min): at baseline and at 120 and $360 \mathrm{~min}$.

\section{Statistical analysis}

Results are given as means $\pm \mathrm{SD}$. One-way and two-way analyses of variance for repeated measures (time, group, and interaction) were used to compare groups where appropriate. Differences with $p$ value less than 0.05 were considered statistically significant. Analyses used the statistical package JMP 5.1 (SAS Institute, Cary, N.C., USA).

\section{Results}

Physiological response to endotoxin

LPS induced reproducible systemic, endocrine, and metabolic effects in both groups, starting about $75 \mathrm{~min}$ after LPS injection (Table 1). All subjects complained of headache, nausea, and muscle pain.

\section{Systemic effects}

Significant increases in body temperature $\left(+1.9^{\circ} \mathrm{C}\right.$, $p<0.0001)$, heart rate $(+52 \%, p<0.0001)$, and cardiac output $(+40 \%, p<0.0001)$, peaking at $t_{240}$ after LPS were observed in control subjects. Systolic, diastolic, mean blood pressure, and $\mathrm{SpO}_{2}$ did not change significantly.

Hormones, cytokines, and metabolism

LPS induced a marked endocrine response in control subjects (Table 2). At $t_{240}$ ACTH levels were increased 15 times $(p<0.0001)$, cortisol 3 times $(p<0.0001)$, and glucagon $60 \%(p=0.012)$. Both plasma norepinephrine (peak at $t_{120},+252 \%, p<0.001$ ) and epinephrine (peak at $t_{240},+117 \%, p<0.002$ ) increased strongly. Insulin levels showed a temporary decrease at $t_{120}$ and then reached basal levels. Following LPS TNF- $\alpha$ levels increased 110 times at $t_{120}(p<0.0001)$ while IL-6 levels peaked at $t_{180}(p<0.0001)$. Plasma glucose

Table 1 Effect of endotoxin on the systemic variables, baroreflex sensitivity, and heart rate variability

\begin{tabular}{|c|c|c|c|c|c|c|c|}
\hline & $t_{0}$ & $\mathrm{t}_{30}$ & $\mathrm{t}_{60}$ & $\mathrm{t}_{120}$ & $\mathrm{t}_{180}$ & $t_{240}$ & $\mathrm{t}_{360}$ \\
\hline \multicolumn{8}{|l|}{ Control } \\
\hline Temperature $\left({ }^{\circ} \mathrm{C}\right)$ & $36.8 \pm 0.3$ & - & $36.9 \pm 0.2$ & $38.0 \pm 0.5 * *$ & $38.6 \pm 0.5 * *$ & $38.7 \pm 0.3 * *$ & $38.0 \pm 0.3 * *$ \\
\hline Heart rate (bpm) & $59 \pm 7$ & - & $64 \pm 6$ & $75 \pm 8 * *$ & $87 \pm 9 * *$ & $88 \pm 9 * *$ & $82 \pm 9 * *$ \\
\hline Cardiac output (\%) & 100 & - & $96 \pm 12$ & $118 \pm 16$ & $131 \pm 33^{*}$ & $140 \pm 45^{* *}$ & $125 \pm 30^{*}$ \\
\hline Respiratory rate (bpm) & $15 \pm 1$ & - & $15 \pm 2$ & $18 \pm 2 * *$ & $17 \pm 3 *$ & $15 \pm 2$ & $13 \pm 1$ \\
\hline $\begin{array}{l}\text { Baroreflex sensitivity } \\
\left(\mathrm{m} \mathrm{s}^{-1} \mathrm{mmHg}^{-1}\right)\end{array}$ & - & $12.25 \pm 3.67$ & $7-$ & $11.23 \pm 4.61$ & - & - & $5.78 \pm 2.04$ \\
\hline $\operatorname{LF}\left(\mathrm{m} \mathrm{s}^{-2}\right)$ & - & $1499 \pm 1486$ & - & $2134 \pm 1226$ & - & - & $627 \pm 538^{*}$ \\
\hline $\mathrm{HF}\left(\mathrm{m} \mathrm{s}^{-2}\right)$ & - & $797 \pm 845$ & - & $753 \pm 517$ & - & - & $144 \pm 117 *$ \\
\hline LF/HF ratio & - & $2.0 \pm 0.8$ & - & $3.7 \pm 1.5 *$ & - & - & $4.7 \pm 1.6^{* *}$ \\
\hline \multicolumn{8}{|l|}{ Fish oil } \\
\hline Temperature $\left({ }^{\circ} \mathrm{C}\right)$ & $36.7 \pm 0.1$ & - & $36.8 \pm 0.2$ & $37.3 \pm 0.3 * *$ & $37.9 \pm 0.3 * *$ & $38.1 \pm 0.2^{* *}$ & $37.7 \pm 0.3 * *$ \\
\hline Heart rate (bpm) & $63 \pm 10$ & - & $64 \pm 7$ & $78 \pm 7 * *$ & $89 \pm 4 * *$ & $88 \pm 5^{* *}$ & $78 \pm 10 * *$ \\
\hline Cardiac output (\%) & 100 & - & $101 \pm 7$ & $113 \pm 18$ & $137 \pm 27 * *$ & $134 \pm 17 *$ & $121 \pm 17 *$ \\
\hline Respiratory rate (bpm) & $14 \pm 2$ & - & $14 \pm 1$ & $16 \pm 2$ & $16 \pm 2$ & $14 \pm 1$ & $14 \pm 1$ \\
\hline $\begin{array}{l}\text { Baroreflex sensitivity } \\
\left(\mathrm{m} \mathrm{s}^{-1} \mathrm{mmHg}^{-1}\right)\end{array}$ & - & $12.37 \pm 3.04$ & +- & $10.07 \pm 5.68$ & - & - & $8.03 \pm 2.42$ \\
\hline $\mathrm{LF}\left(\mathrm{m} \mathrm{s}^{-2}\right)$ & - & $1480 \pm 1169$ & - & $1884 \pm 1966$ & - & - & $754 \pm 592 *$ \\
\hline $\mathrm{HF}\left(\mathrm{m} \mathrm{s}^{-2}\right)$ & - & $897 \pm 780$ & - & $751 \pm 1068$ & - & - & $301 \pm 394^{*}$ \\
\hline $\mathrm{LF} / \mathrm{HF}$ ratio & - & $1.7 \pm 0.7$ & - & $3.2 \pm 1.1 *$ & - & - & $3.8 \pm 1.7 *$ \\
\hline
\end{tabular}

$* p<0.05, * * p<0.01$ vs. baseline 
Table 2 Effect of endotoxin on hormones, cytokines and energy metabolism

\begin{tabular}{|c|c|c|c|c|c|c|}
\hline & $\mathrm{t}_{0}$ & $t_{60}$ & $t_{120}$ & $\mathrm{t}_{180}$ & $\mathrm{t}_{240}$ & $t_{360}$ \\
\hline \multicolumn{7}{|l|}{ Control } \\
\hline ACTH (ng/l) & $23 \pm 7$ & - & $152 \pm 66^{*}$ & - & $347 \pm 204^{*}$ & $36 \pm 28$ \\
\hline Cortisol $(\mathrm{nmol} / \mathrm{l})$ & $273 \pm 92$ & - & $551 \pm 123 *$ & _- & $678 \pm 208^{*}$ & $458 \pm 222 *$ \\
\hline Epinephrine (pg/ml) & $37 \pm 21$ & - & $68 \pm 30^{*}$ & - & $79 \pm 51^{*}$ & $44 \pm 15$ \\
\hline Norepinephrine (pg/ml) & $186 \pm 51$ & - & $653 \pm 276^{*}$ & - & $169 \pm 35$ & $176 \pm 51$ \\
\hline Insulin $(\mathrm{mU} / \mathrm{ml})$ & $7.7 \pm 2.1$ & $8.1 \pm 2.4$ & $7.2 \pm 1.1$ & - & $7.7 \pm 1.6$ & $7.6 \pm 1.5$ \\
\hline Glucagon (ng/l) & $66 \pm 22$ & $65 \pm 20$ & $94 \pm 45^{*}$ & - & $103 \pm 28 *$ & $86 \pm 28 *$ \\
\hline TNF- $\alpha(\mathrm{pg} / \mathrm{ml})$ & $5.8 \pm 8.2$ & $413.1 \pm 267.1^{*}$ & $686.9 \pm 554.7 *$ & $296.2 \pm 206.4 *$ & $96.2 \pm 41.6$ & - \\
\hline IL-6 (pg/ml) & - & $19 \pm 30$ & $540 \pm 634 *$ & $617 \pm 642 *$ & $237 \pm 151$ & - \\
\hline hs-CRP (mg/l) & $0.4 \pm 0.2$ & - & - & - & - & $3.0 \pm 0.9$ \\
\hline $\begin{array}{l}\text { Energy expenditure } \\
\text { (kcal/min) }\end{array}$ & $1.1 \pm 0.2$ & $1.1 \pm 0.2$ & $1.4 \pm 0.2^{*}$ & $1.5 \pm 0.3^{*}$ & $1.5 \pm 0.2^{*}$ & $1.3 \pm 0.2 *$ \\
\hline Glycemia (mg/dl) & $89.3 \pm 4.7$ & $88.0 \pm 6.0$ & $80.4 \pm 8.5^{*}$ & $88.5 \pm 6.1$ & $92.3 \pm 6.0$ & $93.0 \pm 6.3$ \\
\hline Lactate $(\mathrm{mmol} / \mathrm{l})$ & $0.9 \pm 0.2$ & $0.9 \pm 0.3$ & $1.6 \pm 0.4^{*}$ & $1.3 \pm 0.4$ & $1.0 \pm 0.3$ & $0.9 \pm 0.2$ \\
\hline Free fatty acids $(\mathrm{mmol} / \mathrm{l})$ & $0.40 \pm 0.12$ & $0.46 \pm 0.15$ & $0.75 \pm 0.28 *$ & $0.84 \pm 0.30 *$ & $0.97 \pm 0.25^{*}$ & $1.03 \pm 0.22 *$ \\
\hline Triglycerides (mmol/l) & $0.61 \pm 0.21$ & $0.55 \pm 0.17$ & $0.58 \pm 0.21$ & $0.64 \pm 0.25$ & $0.70 \pm 0.31$ & $0.60 \pm 0.25$ \\
\hline \multicolumn{7}{|l|}{ Fish oil } \\
\hline ACTH (ng/l) & $29 \pm 17$ & - & $109 \pm 80^{*}$ & - & $110 \pm 98^{*}$ & $20 \pm 12$ \\
\hline Cortisol (nmol/l) & $205 \pm 38$ & - & $441 \pm 114 *$ & - & $529 \pm 219^{*}$ & $281 \pm 180$ \\
\hline Epinephrine (pg/ml) & $18 \pm 11$ & - & $37 \pm 20$ & - & $38 \pm 21$ & $33 \pm 13$ \\
\hline Norepinephrine $(\mathrm{pg} / \mathrm{ml})$ & $195 \pm 77$ & - & $266 \pm 78$ & - & $179 \pm 56$ & $194 \pm 112$ \\
\hline Insulin $(\mathrm{mU} / \mathrm{ml})$ & $10.7 \pm 4.0$ & $10.8 \pm 3.5$ & $9.9 \pm 3.0$ & - & $9.2 \pm 2.4$ & $9.4 \pm 2.5$ \\
\hline Glucagon (ng/l) & $65 \pm 12$ & $63 \pm 11$ & $80 \pm 20$ & - & $81 \pm 21$ & $72 \pm 18$ \\
\hline TNF- $\alpha(\mathrm{pg} / \mathrm{ml})$ & $7.1 \pm 8.4$ & $130.5 \pm 98.3$ & $255.4 \pm 221.5^{*}$ & $118.6 \pm 67.2$ & $47.8 \pm 29.1$ & - \\
\hline IL-6 (pg/ml) & - & $4.8 \pm 10$ & $522 \pm 680 *$ & $595 \pm 900 *$ & $227 \pm 356$ & - \\
\hline hs-CRP (mg/l) & $0.5 \pm 0.3$ & - & - & - & - & $2.6 \pm 1.4$ \\
\hline $\begin{array}{l}\text { Energy expenditure } \\
(\mathrm{kcal} / \mathrm{min})\end{array}$ & $1.1 \pm 0.1$ & $1.1 \pm 0.1$ & $1.2 \pm 0.2$ & $1.4 \pm 0.3^{*}$ & $1.3 \pm 0.2 *$ & $1.2 \pm 0.2$ \\
\hline Glycemia (mg/dl) & $92.2 \pm 5.6$ & $90.6 \pm 4.5$ & $85.9 \pm 3.2^{*}$ & $91.4 \pm 6.5$ & $94.7 \pm 8.2$ & $93.8 \pm 8.6$ \\
\hline Lactate $(\mathrm{mmol} / \mathrm{l})$ & $1.1 \pm 0.3$ & $0.9 \pm 0.2$ & $1.2 \pm 0.4$ & $1.2 \pm 0.6$ & $1.1 \pm 0.4$ & $1.0 \pm 0.4$ \\
\hline Free fatty acids $(\mathrm{mmol} / \mathrm{l})$ & $0.24 \pm 0.11$ & $0.28 \pm 0.11$ & $0.33 \pm 0.18$ & $0.46 \pm 0.18^{*}$ & $0.62 \pm 0.26^{*}$ & $0.64 \pm 0.22 *$ \\
\hline Triglycerides $(\mathrm{mmol} / \mathrm{l})$ & $0.99 \pm 0.73$ & $0.87 \pm 0.54$ & $0.84 \pm 0.42$ & $0.81 \pm 0.39 *$ & $0.76 \pm 0.36^{*}$ & $0.60 \pm 0.31 *$ \\
\hline
\end{tabular}

$* p<0.05, * * p<0.01$ vs. baseline

concentration changes after LPS were not statistically significant. Plasma lactate increased from $t_{60}$ and peaked at $t_{120}(+76 \%, p=0.09)$. A sustained increase in REE $(+38 \%, p<0.0001)$ starting at $t_{90}$ was observed. FFA increased significantly from baseline until the end of the test $(+162 \%, p<0.0001)$. Net fat oxidation increased significantly $(+210 \%, p=0.001)$.

Baroreflex sensitivity and heart rate variability

Baroreflex sensitivity decreased significantly between baseline and the end of the test $(p=0.002)$. LF power tended to increased from $t_{30}$ to $t_{120}$ and then markedly decreased at $t_{360}\left(p=0.04\right.$ from $t_{120}$ to $\left.t_{360}\right)$. HF power remained stable between $t_{30}$ and $t_{120}$ and then significantly decreased at $t_{360}(p=0.012)$. The $\mathrm{LF} / \mathrm{HF}$ ratio, a surrogate for sympathovagal balance, increased significantly over time $(p<0.0001)$.

\section{Effect of FO on the physiological response to LPS}

Baseline plasma lipids did not differ: cholesterol $4.4 \pm 0.3 \mathrm{mmol} / \mathrm{l} \quad$ (control) $\quad$ vs. $4.2 \pm 0.3 \quad$ (FO) and triglycerides $0.99 \pm 0.72$ vs. $0.61 \pm 0.21 \mathrm{mmol} / \mathrm{l}$. The triglyceride profile differed during the study between groups $(p<0.001)$, with a progressive decrease in the control groups and stable levels in the FO group in relation to lipid administration (Table 2). The composition of platelet membrane was affected by FO infusions, with significant incorporation of EPA $(p=0.0002)$ and DHA $(p=0.02$, Fig. 1). Significant differences were observed in body temperature and the neuroendocrine response between the FO and control groups. The increase in body temperature was attenuated in the FO group after LPS: peak temperature reached $38.1{ }^{\circ} \mathrm{C}\left(+1.4^{\circ} \mathrm{C}\right)$ in the FO group vs. $38.7^{\circ} \mathrm{C}\left(+1.9^{\circ} \mathrm{C}\right)$ in controls. The difference was significant from $t_{120}$ until $t_{360}(p=0.003$ to $p=0.022$; Fig. 2). The adrenocortical and sympathoadrenal responses 
Fig. 1 Composition of platelet membrane before and after fish oil infusion expressed as percentage of membrane fatty acids: n-3 PUFA are incorporated into cell membrane phospholipids after two doses of fish oil. (Data available for only five volunteers due to technical problems)

Fig. 2 Course of plasma TNF- $\alpha$ and temperature in the fish oil and control groups after LPS injection
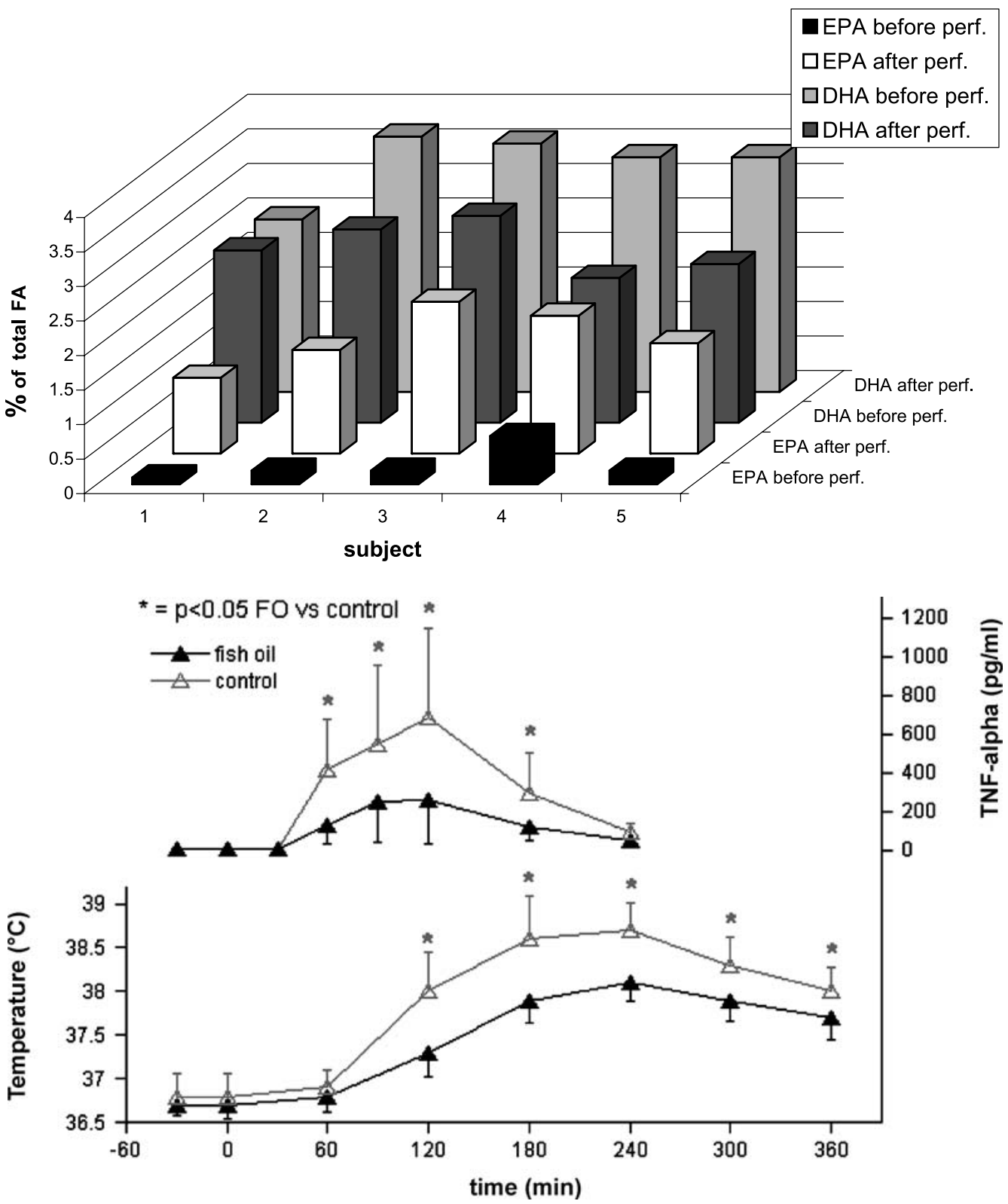

to LPS were blunted by FO: the rise in plasma norepi- between $t_{60}$ and $t_{180}(p=0.022$ to $p=0.038$ ), but IL- 6 valnephrine was sevenfold lower $(p=0.02$; Fig. 3). Plasma ues did not differ between groups. REE variability was epinephrine was unchanged. ACTH peak at $t_{240}$ was four substantial in both groups, particularly in the subjects with times lower in the FO group than in controls $(p=0.02)$. marked shivering (trend to lower REE in the FO group). Plasma cortisol was lower in the FO group but the Heart rate, cardiac output, respiratory rate, arterial presdifference was not statistically significant $(p=0.07)$. sure, baroreflex sensitivity, and HRV response to LPS did TNF- $\alpha$ was also significantly lower in the FO group not differ between groups. 
Fig. 3 Plasma concentrations of ACTH and norepinephrine in the fish oil and control groups after LPS injection

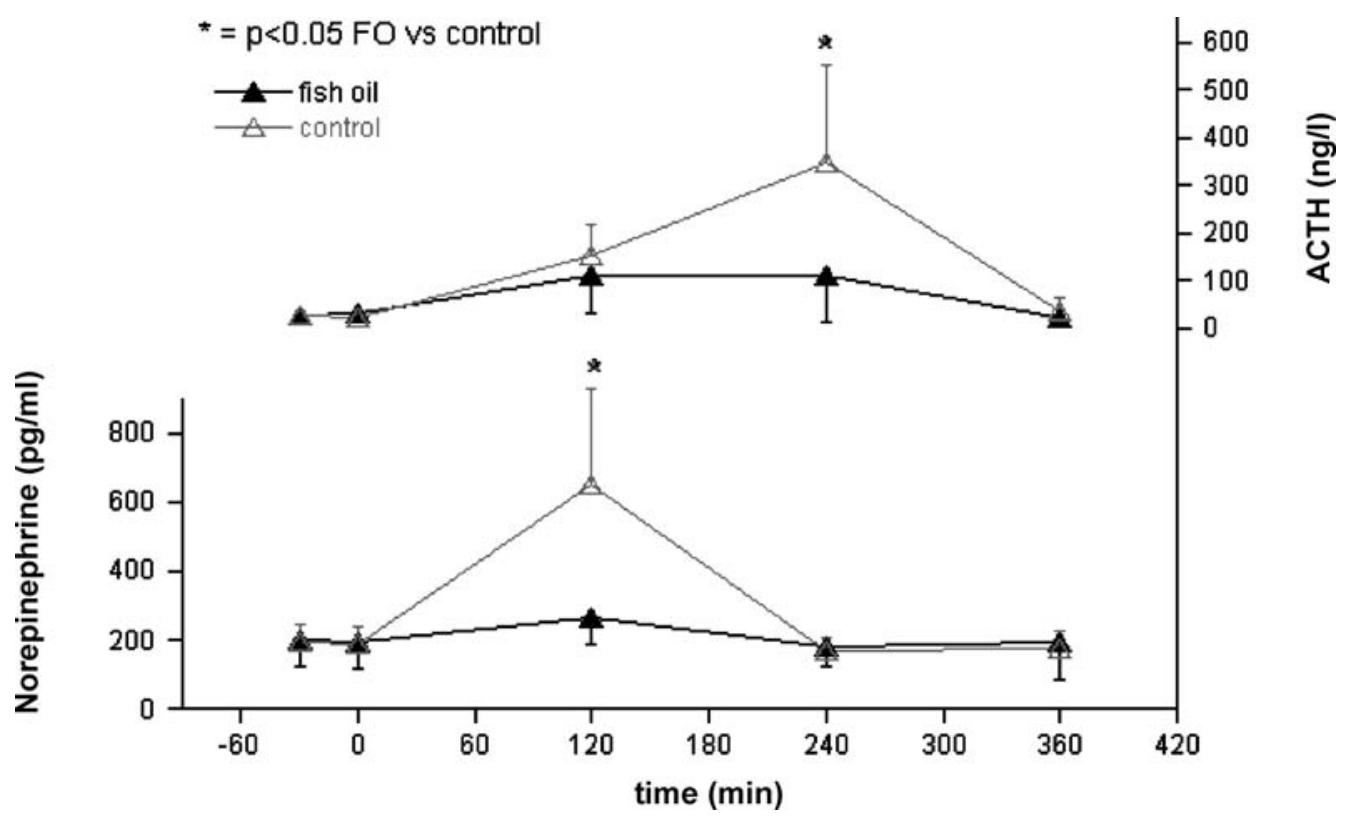

\section{Discussion}

In this human model of intravenous LPS FO lipid emulsion blunted important aspects of the response. Fever was reduced while the hypothalamo-pituitary adrenal and sympathethic responses were blunted. Some aspects of the inflammatory response as well as the sympathovagal balance were altered.

Effects of LPS injection in healthy subjects

Intravenous LPS induces an acute inflammatory state in healthy humans and animals, which mimics some pathophysiological aspects of sepsis [8]: a flulike state rapidly develops, with fever, muscle ache, tachycardia, sweating, and nausea. Mononuclear cells are activated to release proinflammatory cytokines, while the complement and coagulation cascades are activated $[9,10]$. A typical neuroendocrine response transiently occurs. Resting metabolic rate, glucose turnover, and protein catabolism are increased [11]. LPS also exerts a demonstrable effect on HRV, a surrogate parameter of sympathetic and parasympathetic control on heart rate. Healthy subjects receiving endotoxin present reduced HRV, as do critical care patients suffering sepsis [12]. Analysis within the frequency domain indicates that the $\mathrm{LF} / \mathrm{HF}$ power ratio was increased. This observation is usually interpreted as a marker of sympathetic nerve activity. HRV was affected by LPS: HF decreased slightly compared to baseline, suggesting a small change in vagal activity. By contrast, LF power markedly increased, indicating a consistent increase in sympathetic tone. At the end of the test HF power decreased, demonstrating a large reduction in parasympathetic activity. Changes in baroreflex sensitivity similarly reflect the modifications in sympathovagal balance. It is interesting to observe that baroreflex sensitivity changed only slightly at $t_{120}$, whereas it was markedly reduced at $t_{360}$. This suggests that under these experimental conditions baroreflex sensitivity is more dependent on changes in vagal tone than on changes in sympathetic activity.

Effects of n-3 PUFAs on acute inflammation

Various strategies have been used to affect the course of sepsis in addition to eradication of the septic or inflammatory sites. Recent research has focused on the development of specific nutrients influencing the organ and system functions as well as the responses to critical illness [13], such as n-3 PUFAs [1]. FO infusion in guinea pigs enhances survival following lethal LPS dose [14]. Intravenous FO has been shown to prevent the LPSinduced reduction in blood flow to the gut and to reduce bacterial translocation after exposure to live bacteria in the rat [15]. FO in guinea pigs and rats is associated with better perfusion in vital organs, improved metabolic adaptation, and reduced fever and weight loss [15-19]. In a previous study in healthy subjects our group showed that prolonged supplementation with oral FO blunts the neuroendocrine and inflammatory responses to LPS challenge [20]. Perioperative administration of n-3 fatty acids may favorably affect the postoperative outcome of surgical patients [21]. Recent data in critically ill patients suggest that FO supplemented parenteral nutrition improves survival, infection rate, and length of stay [4]. 


\section{Central effects: stress and fever}

The response to stress has traditionally been viewed as a consequence of the neuroendocrine activation, initiated by tissue injury and by cortical and noncortical signals from the central nervous system [22]. This response is characterized by the activation of the sympathoadrenal system and the hypothalamopituitary axis [23]. In healthy subjects 3-4 weeks of oral FO inhibited the adrenal activation elicited by mental stress [24], confirming previous data in subjects subjected to typhoid vaccine after 6 weeks of enteral FO [25]. However, the difference in body temperature between FO and saline was not significant, which limits the evidence. In our experiments FO given before LPS significantly attenuated fever and stress hormones production. This is an argument in favor of a central effect of n-3 PUFAs, downregulating temperature and sympathetic and adrenocortical axes.

The finding of decreased sympathetic nervous system activity in our study associated with a lower parasympathetic inhibition after FO may translate into a reduced arrythmogenic risk. Failure to reach statistical significance with HRV and baroreflex variability may be related to the fact these variables are indirect evaluations of sympathetic activity, with relatively low sensitivity compared to more direct approaches such as microneurography or plasma norepinephrine turnover. This result is in agreement with the significant suppression by FO of plasma norepinephrine, a component of sympathetic activation. The relative inhibition of the central and sympathetic activity and the adrenal medulla could not be assessed with the present study design.

Fever is mediated by complex peripheral and central mechanisms, involving prostaglandin $\mathrm{E}_{2}$, a mediator derived from arachidonic acid. The latter is produced in response to cytokines and other mediators. Both in experimental and clinical settings n-3 PUFA have been shown to downregulate the temperature response to inflammation [18, 20, 25]. In our study prostaglandin and their derivates were not determined, and therefore we can only speculate that this might have been one of the underlying mechanisms of fever attenuation.

\section{Inflammatory response}

The n-3 PUFAs may modulate the inflammatory response by complex mechanisms involving the activity of transcriptional factors, such as nuclear factor $\kappa \mathrm{B}$, peroxisome proliferator activated receptors, and sterol regulatory element binding protein as well as Toll-like receptors [26]. They also downregulate proinflammatory cytokine production by human monocytes in vitro and in vivo [27]. In patients undergoing abdominal surgery provision of parenteral nutrition supplemented with n-3 PUFAs induced decreased levels of plasma TNF- $\alpha$ and IL-6 in comparison with $n-6$ fatty acids [28]. In the present study TNF- $\alpha$ concentrations increase was blunted in the FO group, confirming an anti-inflammatory effect of FO. By contrast, IL-6 plasma levels did not differ between groups, probably due to the short lasting effect of endotoxin.

\section{Influence of the route of administration}

The composition and characteristics of cell membranes is dependent on the diet composition. In Western populations the n-3 PUFA content of mononuclear cell membranes is low, as observed in our healthy volunteers. This may affect many important cell functions such as membrane fluidity, opening of ion channels, recognition and function of membrane receptors, eicosanoid synthesis, second messenger synthesis, and many signaling pathways [29]. In our study FO was infused to achieve rapid membrane incorporation, as shown by the rapid increase in the EPA and DHA cell membrane content. This corresponds to a pharmacological effect where nutrients are administered to modulate organ and system functions.

Such rapid delivery of specific compound to the target cells and organs is difficult to achieve with enteral administration of triacylglycerols containing long-chain PUFAs such as DHA and EPA since the hydrolysis of these compounds by the pancreatic lipase is rather slow. Furthermore, hydrolysis of lipoprotein triacylglycerols by lipoprotein lipase is also a slow process with a low efficiency. As a consequence the use of the intravenous route which bypasses the intestinal process of absorption and therefore decreases the delay of action seems attractive. In our study only two doses of a lipid emulsion containing $10 \%$ of FO significantly modified the cell membrane composition and the responses to endotoxin. Such a rapid effect may lead to potential indications for early intervention with FO.

\section{Limitations of the study}

The study was designed as a pharmacological investigation comparing FO lipid emulsion as a drug with no treatment. Such solution contains glycerol, phosphatidyl-choline, and some linoleic and linolenic acid and tocopherol in addition to EPA and DHA. Although these PUFAs were the principal components, and their incorporation into platelets could be confirmed, our results may also be interpreted as an effect of either of the components of the lipid emulsion. Finally lipid emulsions have been shown to blunt the response to LPS in vitro and in vivo [30]. This protection is achieved through the binding and neutralization of LPS 
by circulating lipoproteins [31]. In our trial the lipoprotein profile was not determined, and we therefore cannot conclude on this aspect. Another theoretical limitation is related to the absence of saline perfusion in the control subjects, to avoid unnecessary cannulations before the study day. It is seems very unlikely, however, that this design affected the results considering that basal values were measured on the day of the test only.

In conclusion, our results indicate that acute intravenous FO lipid emulsion administration was rapidly incorporated into cell membrane and downregulated the neuroendocrine and metabolic responses to LPS in healthy humans. This suggests that intravenous FO exerts beneficial effects in acute medicine by modulating the stress and inflammatory responses.

Acknowledgements. The authors thank Mrs. Marie-Christine Cayeux (RN) and Mrs. Ludivine Soguel Alexander (RD) for their help, Mrs. A. Dufour and A. Chwalik (Université Libre de Bruxelles, Brussels, Belgium) for fatty acid analyses in platelet membranes, Ing. Paolo Castiglioni (PhD.) for helpful discussions, and Mr. P. Frascarolo (PhD.) for help with statistical outwork. The present study was performed with the support of the Swiss Fond National de Recherche, grant no. 3200B0-102064. Experimental emulsions were kindly provided by Fresenius Kabi AG (Bad Homburg, Germany).

\section{References}

1. Calder PC (2004) n-3 fatty acids, inflammation, and immunity-relevance to postsurgical and critically ill patients. Lipids 39:1147-1161

2. Mayer K, Gokorsch S, Fegbeutel C, Hattar K, Rosseau S, Walmrath D, Seeger W, Grimminger F (2003) Parenteral nutrition with fish oil modulates cytokine response in patients with sepsis. Am J Respir Crit Care Med 167:1321-1328

3. Calder PC (2006) Use of fish oil in parenteral nutrition: rationale and reality. Proc Nutr Soc 65:264-277

4. Heller AR, Rossler S, Litz RJ, Stehr SN, Heller SC, Koch R, Koch T (2006) Omega-3 fatty acids improve the diagnosis-related clinical outcome. Crit Care Med 34:972-979

5. Livesey G, Elia M (1988) Estimation of energy expenditure, net carbohydrate utilization, and net fat oxydation and synthesis by indirect calorimetry: evaluation of errors with special reference to the detailed composition of fuels. Am J Clin Nutr 47:608-628

6. Parati G, Di Rienzo M, Bertinieri G, Pomidossi G, Casadei R, Groppelli A, Pedotti A, Zanchetti A, Mancia G (1988) Evaluation of the baroreceptorheart rate reflex by 24 -hour intra-arterial blood pressure monitoring in humans. Hypertension 12:214-222

7. Bertinieri G, Di Rienzo M, Cavallazzi A, Ferrari A. U, Pedotti A, Mancia G (1988) Evaluation of baroreceptor reflex by blood pressure monitoring in unanesthetized cats. Am J Physiol 254:H377-H383

8. Lin E, Lowry SF (1998) The human response to endotoxin. Sepsis 2:255-262

9. Van der Poll T, Romijn JA, Endert E, Born JJJ, Büller HR, Sauerwein HP (1991) Tumor necrosis factor mimics the metabolic response to acute infection in healthy humans. Am J Physiol 261:H457-H465
10. Spinas GA, Keller U, Brockhaus M (1992) Release of soluble receptors for tumor necrosis factor (TNF) in relation to circulating TNF during experimental endotoxinemia. J Clin Invest 90:533-536

11. Bloesch D, Keller U, Spinas GA, Kury D, Girard J, Stauffacher W (1993) Effects of endotoxin on leucine and glucose kinetics in man: contribution of prostaglandin E2 assessed by a cyclooxygenase inhibitor. J Clin Endocrinol Metab 77:1156-1163

12. Schmidt H, Muller-Werdan U, Hoffmann T, Francis DP, Piepoli MF, Rauchhaus M, Prondzinsky R, Loppnow H, Buerke M, Hoyer D, Werdan K (2005) Autonomic dysfunction predicts mortality in patients with multiple organ dysfunction syndrome of different age groups. Crit Care Med 33:1994-2002

13. Chiolero R, Kinney JM (2001) Metabolic and nutritional support in critically ill patients: feeding the whole body or individual organs? Curr Opin Clin Nutr Metab Care 4:127-130

14. Mascioli E, Leader L, Flores E, Trimbo S, Bistrian B, Blackburn G (1988) Enhanced survival to endotoxin in guinea pigs fed IV fish oil emulsion. Lipids 23:623-625

15. Pscheidl E, Schywalsky M, Tschaikowsky K, Böke-Pröls T (2000) Fish oil-supplemented parenteral diets normalize splanchnic blood flow and improve killing of translocated bacteria in a low-dose endotoxin rat model. Crit Care Med 28:1489-1496

16. Ellis EF, Police RJ, Dodson LY, McKinney JS, Holt SA (1992) Effect of dietary n-3 fatty acids on cerebral microcirculation. Am J Physiol 262:H1379-H1386
17. Pomposelli JJ, Flores E, Hirschberg Y, Teo TC, Blackburn GL, Zeisel SH, Bistrian BR (1990) Short-term TPN containing $n-3$ fatty acids ameliorate lactic acidosis induced by endotoxin in guinea pigs. Am J Clin Nutr 52:548-552

18. Pomposelli JJ, Mascioli EA, Bistrian BR, Lopes SM, Blackburn GL (1989) Attenuation of the febrile response in guinea pigs by fish oil enriched diets. JPEN J Parenter Enteral Nutr 13:136-140

19. Teo TC, Selleck KM, Wan JM, Pomposelli JJ, Babayan VK, Blackburn GL, Bistrian BR (1991) Long-term feeding with structured lipid composed of medium-chain and N-3 fatty acids ameliorates endotoxic shock in guinea pigs. Metabolism 40:1152-1159

20. Michaeli B, Berger MM, Revelly JP, Tappy L, Chiolero R (2007) Effects of fish oil on the neuro-endocrine responses to an endotoxin challenge in healthy volunteers. Clin Nutr 26:70-77

21. Weiss G, Meyer F, Matthies B, Pross M, Koenig W, Lippert H (2002) Immunomodulation by perioperative administration of n-3 fatty acids. Br J Nutr 87 Suppl 1:S89-S94

22. Assenmacher I, Barbanel G, Gaillet S, Givalois L, Ixart G, Malaval F, Mekaouche M, Siaud P, Szafarczyk A (1995) Central regulation of ACTH release in stress. Ann N Y Acad Sci 771:41-54

23. Chrousos GP (1995) The hypothalamicpituitary-adrenal axis and immunemediated inflammation. N Engl J Med 332:1351-1362

24. Delarue J, Matzinger O, Binnert C, Schneiter P, Chiolero R, Tappy L (2003) Fish-oil prevents the adrenal activation elicited by mental stress in healthy men. Diabet Med 29:289-295 
25. Copper AL, Gibbons L, Horan MA, Little RA, Rothwell NJ (1993) Effect of dietary fish oil supplementation on fever and cytokine production in human volunteers. Clin Nutr 12:3212-3328

26. Lee JY, Plakidas A, Lee WH, Heikkinen A, Chanmugam P, Bray G, Hwang DH (2003) Differential modulation of Toll-like receptors by fatty acids: preferential inhibition by $n-3$ polyunsaturated fatty acids. J Lipid Res 44:479-486
27. Endres S, Ghorbani R, Kelley VE, Georgilis K, Lonnemann G, van der Meer JW, Cannon JG, Rogers TS, Klempner MS, Weber PC et al (1989) The effect of dietary supplementation with n-3 polyunsaturated fatty acids on the synthesis of interleukin- 1 and tumor necrosis factor by mononuclear cells. N Engl J Med 320:265-271

28. Wachtler P, Konig W, Senkal M, Kemen M, Koller M (1997) Influence of a total parenteral nutrition enriched with omega-3 fatty acids on leukotriene synthesis of peripheral leukocytes and systemic cytokine levels in patients with major surgery. J Trauma 42:191-198
29. Carpentier YA, Dupont IE (2002) Optimizing intravenous supply of functional lipid components. Nestle Nutr Workshop Ser Clin Perform Programme 7:87-98

30. Harris HW, Johnson JA, Wigmore SJ (2002) Endogenous lipoproteins impact the response to endotoxin in humans. Crit Care Med 30:23-31

31. Feingold KR, Funk JL, Moser AH, Shigenaga JK, Rapp JH, Grunfeld C (1995) Role for circulating lipoproteins in protection from endotoxin toxicity. Infect Immun 63:2041-2046 